\title{
"OS QUILOMBOLA VEM DA PARTE DOS MORENOS, NÉ? DAÍ DA ÁFRICA": IDENTIDADES QUILOMBOLAS ENTRE OS MORADORES DA COMUNIDADE DE JURUSSACA
}

\author{
Glayce de Fátima Fernandes da Silva ${ }^{1}$
}

\begin{abstract}
RESUMO
A partir de trabalho de campo na comunidade de Jurussaca, Tracuateua/PA (localizada na Amazônia Oriental) este artigo aborda a temática das identidades quilombola. Interpreta e reflete sobre a construção das identidades dos moradores da comunidade de Jurussaca como quilombolas. A identidade social dos moradores de Jurussaca (como quilombolas) foi elaborada (em um primeiro plano) a partir de quatro elementos: a origem comum, a luta pela posse da terra e titulação coletiva, a cor da pele (ser preto) e no sobrenome comum (Araújo), somados a outros elementos dessa identidade (em um segundo plano): as relações de parentesco, o pertencimento e as redes de parentesco, além das práticas religiosas e crenças presentes na comunidade. Todos esses elementos (do primeiro e do segundo plano) representam as identidades quilombolas circulantes na comunidade de Jurussaca, mas, além disso, representam um grupo cuja formação recebeu forte influência afro-indígena (SILVA, 2014) e que muito representa a população amazônica, em especial as comunidades da Região do Salgado Paraense. Este trabalho destaca apenas algumas dessas identidades.
\end{abstract}

Palavras-chave: Comunidade Quilombola. Jurussaca. Identidades

\begin{abstract}
This work it was developed in the Jurussaca community, Tracuateua/PA (located in the Eastern Amazon) and deals with the quilombolas identities theme. Interprets and reflects on the construction of identities of the Jurussaca community residents as quilombolas. The social identity of the inhabitants of Jurussaca (as quilombolas) was developed (in a foreground) from four elements: common origin, struggle for land ownership and collective titling, skin color (being black) and common surname (Araújo), added to other elements of this identity (in background): kinship relations, belonging and kinship networks, besides the religious practices and beliefs present in the community. All these elements (in foreground and background) represent the circulating quilombolas identities in the Jurussaca community, but, moreover, represent a group whose formation received strong Afro-Indian influence (SILVA, 2014), which quite represents the Amazonian population, especially the communities of the Paraense Salgado region. This work highlights only a few of these identities
\end{abstract}

Keywords: Quilombola Community. Jurussaca. Identities.

\section{INTRODUÇÃO}

Este artigo é um recorte da pesquisa desenvolvida para a produção da Dissertação de Mestrado, apresentada ao Programa de Pós-Graduação em Linguagens e Saberes na Amazônia (UFPA), e concentra atenção às identidades quilombolas na/da comunidade de Jurussaca.

\footnotetext{
${ }^{1}$ Mestre pelo Programa de Pós-Graduação em Linguagens e Saberes na Amazônia, Universidade Federal do Pará (UFPA), glaycesilv@gmail.com
} 
A comunidade de Jurussaca fica localizada no município de Tracuateua, ao nordeste do estado paraense, na Amazônia Oriental. As terras da comunidade de Jurussaca são definidas como terras de preto e de índio (SILVA, 2014), dados seus processos de ocupação e formação afro-indígena.

Não pretendo definir e/ou delimitar as identidades da/na comunidade de Jurussaca. Proponho-me a fazer breves interpretações e reflexões sobre algumas das identidades circulantes na comunidade. Uma vez a construção das identidades quilombolas entre os moradores da comunidade se manifestam em diversos elementos, uns em maior relevo que outros.

Neste artigo destaco apenas alguns desses elementos, como: a cor da pele (ser preto), o sobrenome comum (Araújo), as relações de parentesco (estabelecidas com predominância nas uniões maritais), as redes de parentesco (nos trabalhos coletivos), e no pertencimento (sentimento de pertencimento ao território e/ou ao grupo).

A comunidade de Jurussaca (re)significa continuamente suas identidades, territorialidades e religiosidades. Neste artigo apenas lançamos um breve olhar às questões referentes às identidades, reconhecendo-as como diversas e fluidas (inacabadas).

\section{ALGUMAS VISITAÇÕES CONCEITUAIS}

O conceito de identidade é desdobrado em diferentes campos das ciências sociais (Psicologia, Antropologia, Sociologia...) em meio ao fluxo contínuo de reconstrução Hall (2003). As identidades do homem pós-moderno são fragmentadas, são influenciadas por novos valores, em uma sociedade cujo contato entre os grupos sociais se estabelece de forma mais frequente e dinâmico, desde as maiores às menores esferas sociais. "As comunidades locais, construídas na ação coletiva e preservadas pela memória coletiva, são fortemente específicas de identidade" (CASTELLS, 1997, p. 64 apud BOURDIN, 2001, p. 43).

No entanto, essas identidades são, predominantemente, reações de defesas (mesmo que inconscientes) das comunidades locais contra a imposição da desordem global, que gera mudanças rápidas e inevitáveis. "Elas constroem refúgios, não paraísos" (CASTELLS, 1997, p. 64 apud BOURDIN, 2001, p. 43).

Desse modo, os processos de mudanças históricas afetam igualmente às comunidades locais, que reafirmam identidades comunitárias, ao passo que aderem a elementos culturais globais em sua identidade. Assim, ao nos propormos a abordar questões referentes às identidades presentes na comunidade de Jurussaca (uma comunidade local), consideramos, 
antes de tudo, o seu caráter dinâmico, dado seu contexto histórico atual e seu processo de formação. Dessa maneira, a identidade é compreendida neste estudo a partir de seu caráter relacional, construído a partir do contato com outros, seja no sentido individual, seja no sentido coletivo.

Antes de explanar sobre as identidades no Jurussaca cabe fazermos três definições: identidade étnico-racial e identidade negra no Brasil (LIMA, 2008), identidade quilombola (LITTLE, 2004) e a atualização do conceito de quilombo (SCHMITT; TURATTI; CARVALHO, 2002).

Ao buscar compreender a identidade étnico-racial no Brasil, faz-se necessário termos em mente que diversos repertórios afro-brasileiros influenciaram e influenciam na construção dessa identidade, repertórios esses "constituídos nas suas singularidades a partir de dispositivos culturais e étnicos de origem africana, parte de ampla diversidade" (LIMA, 2008, p. 36). Ainda que essa identidade esteja perpassada por ideologias de "mestiçagem", que segundo Lima (2008) consistem no embranquecimento da população, que por um lado vai de encontro à construção da identidade negra e por outro lado viabiliza a ascensão social (individualmente):

É apresentada como embranquecimento e constitui-se e tem sido historicamente usada como mais um dos mecanismos que vão contra a construção de uma identidade negra brasileira, ao mesmo tempo em que se constitui em mecanismo estratégico que ajuda, em nível individual, na ascensão de negros e mestiços na sociedade brasileira. (LIMA, 2008, p. 36).

Lima (2008) apresenta acima a dicotomia existente na construção da identidade étnicoracial no Brasil. O embranquecimento da sociedade brasileira foi uma ideologia engendrada entre o final do século XIX e meados do século XX e se pautava em dois processos, o biológico (miscigenação) e cultural (sincretismo cultural). O processo de embranquecimento da população brasileira objetivava a continuação de uma sociedade monoétnica e monocultural.

A fim de ampliar a discussão conceitual Lima (2008) explana o conceito contemporâneo de hibridismo ou hibridização, a partir do qual se discute "até que ponto as identidades e as culturas mantêm seus elementos de origem, ou até que ponto esses elementos são identificados como pertencentes a tais grupos" (LIMA, 2008, p. 36). Com isso, a autora não busca discutir a essência da origem da ideologia de embranquecimento, mas colocar em questão as políticas culturais, as redes que estabelecem as negociações e os jogos ideológicos, que inferiorizam alguns e supervalorizam outros. 
Lima (2008) aponta para três conceitos que são centrais para a compreensão das identidades étnico-raciais: afrodescendência, etnia e identidade negra. Paralelo a esses conceitos está o conceito de raça, que representa uma categoria histórica de afrodescendência brasileira e do racismo como instrumento de desigualdade na sociedade brasileira.

As etnias negras no contexto brasileiro são demarcadas pelas raízes históricas sócioculturais e políticas que marcam a formação populacional brasileira no contexto do escravismo e pelas relações estabelecidas tanto nas suas ancestralidades distantes como nas vivências contemporâneas [...] A referência de raça social se configura como parte da questão, pois seu enfoque tem o limite da avaliação do legado africano, ou seja, não basta o reconhecimento de que uma idéia de raça constituía o racismo, mas ter a visão de que a história da população negra é muito mais ampla do que este racismo (LIMA, 2008, p. 38, grifo da autora).

Lima (2008) situa os conceitos de etnia e raça separadamente. O primeiro conceito é demarcado por questões históricas sócio-culturais e políticas, já o segundo se insere como parte desse contexto. Assim, Lima (2008) faz referência ao conceito de raça social como algo inerente a esse contexto macro. A autora define que o conceito de raça social não está engessado à ideia de racismo, mas que engloba a história da população negra. A autora também cita a raça biológica e afirma que "tanto raça biológica como à raça social foram social e culturalmente construídas, apenas sob diferentes argumentos” (LIMA, 2008, p. 39).

As questões étnicas e raciais, portanto, foram construídas a partir de um processo histórico, fruto do "cotidiano das relações sociais", assim como "da luta pelas políticas de promoção de igualdade" (LIMA, 2008). Dessa maneira, sob as múltiplas perspectivas do enfoque étnico e da raça social, esses conceitos devem ser compreendidos a partir da presença, da produção e das políticas públicas para a população negra, ou seja, em seu sentido positivo e não apenas pelas ausências e negações produzidas pelo racismo. Desse modo:

[...] a articulação etnia/raça social torna-se sócio-historicamente mais situado e abrangente e condizente com a multiplicidade identitária que compõe a população afro-brasileira deste país. Atende melhor aos propósitos devido ao maior distanciamento dos biologismos do passado. (LIMA, 2008, p. 39).

Lima (2008) conduz a compreensão do conceito de identidade étnico-racial a partir da contextualização dos conceitos de etnia e raça, abordando-os a partir de diferentes perspectivas e os distanciando das vertentes biológicas e culturais, para então abranger as perspectivas histórica e social.

A identidade negra, por sua vez, de acordo com Lima (2008) está situada entre a identidade de resistência e identidade de projeto. Convergindo com a perspectiva de Hall, que considera complexo pensar sobre as identidades no contexto mundial atual, uma vez que "sua construção está inscrita em relações de poder, de interações materiais e simbólicas e como tal 
não pode ser pensada fora do campo de poder" (LIMA, 2008, p. 42) e, também, com a perspectiva bakhtiniana, considerando os conceitos de dialogismo ou de polifonia (como lugares sociais de conflito e tensão, em que se produzem discursos e sentidos não necessariamente simétricos) (AMORIM, 2003, apud LIMA, 2008).

Outra definição conceitual de igual importância é a identidade quilombola. Para compreendê-la se faz necessário primeiramente voltar um primeiro olhar à Constituição Federal de 1988, que não evoca apenas uma identidade histórica, mas sugere que "qualquer invocação do passado deve corresponder a uma forma atual de existência capaz de realizar-se a partir de outros sistemas de relações que marcam seu lugar num universo social determinado" (O’DWYER, 2002, p.14).

Little (2004) conduz a reflexão sobre ser quilombola no Brasil, para isso reconhece que essa definição está atrelada à questão fundiária no Brasil e à grande diversidade cultural brasileira, apontando para dois grupos importantes dentro dessa diversidade cultural: o grupo indígena (as múltiplas sociedades indígenas) e o grupo de quilombolas (as centenas de comunidades remanescentes de quilombo). Há, no entanto, distintas e variadas formações fundiárias, formadas por diversos grupos, tais como os "açorianos, babaçueiros, caboclos, caiçairas, caipiras, campeiros, jangadeiros, pantaneiros, pescadores artesanais, praicrios, sertanejos e varjeiros" (DIEGUES e ARRUDA, 2001, apud LITTLE, 2004, p. 251).

A essa variedade de grupos humanos Little (2004) aponta para diversas categorias: "populações", "comunidades", "povos", "sociedades", "culturas" - cada uma das quais tende a ser acompanhada por um dos seguintes adjetivos: "tradicionais", "autóctones", "rurais", "locais", "residentes"” (LITTLE, 2004, p. 251). Mas o autor assinala que qualquer dessas combinações é delicada em função da abrangência e da diversidade de grupos que ele engloba, para isso busca definir alguns parâmetros a partir de uma perspectiva etnográfica:

\footnotetext{
De uma perspectiva etnográfica, por exemplo, as diferenças entre as sociedades indígenas, os quilombos, os caboclos, os caiçaras e outros grupos ditos tradicionais além da heterogeneidade interna de cada uma dessas categorias - são tão grandes que não parece viável tratá-los na mesma classificação. Mas, em vez de discutir agora a validade ou não dessas categorias (LITTLE, 2004, p. 252).
}

Ressalta-se que ao esbarrar nessas diversas categorias apontadas por Little (2004) é possível identificar elementos comuns que permeiam esses diversos grupos (que geralmente englobam mais de uma dessas características em sua formação), ainda que cada um deles apresentem suas especificidades. Essa diversidade justifica que alguns autores englobem todos esses grupos na categoria "populações tradicionais". 
Porém, essa variedade de categorias não interfere apenas nos interesses acadêmicos, mas também no cenário político do país, sobretudo nos últimos vinte anos (LITTLE, 2004). Nesse tempo as questões agrárias no Brasil passaram por muitas transformações, decorrentes dos movimentos sociais de reforma agrária, que ganhou bastante força e se consolidou no Brasil na década de 80 , "especialmente no que se refere à demarcação e a homologação das terras indígenas, ao reconhecimento e titulação dos remanescentes de comunidades de quilombos e ao estabelecimento das reservas extrativistas" (LITTLE, 2004, p. 252).

Dessa maneira, não se pode compreender a especificidade de um grupo remanescente quilombola sem ter em mente a gama de categorias que podem estar englobadas em suas identidades.

Nesse sentido, entende-se que as identidades quilombolas na conjuntura atual se apresentam ressignificadas, em contextos específicos, porém, com peculiaridades que as conectam de alguma forma à identidade histórica. Schmitt, Turatti e Carvalho (2002) se propõem a atualizar o conceito de quilombo, a fim de aproximar o termo das atuais configurações de quilombos (comunidades remanescentes quilombolas) existentes no Brasil:

\begin{abstract}
A tarefa de fundamentar teoricamente a atribuição de uma identidade quilombola a um grupo e, por extensão, garantir ainda que formalmente - o seu acesso à terra trouxe à tona a necessidade de redimensionar o próprio conceito de quilombo, a fím de abarcar a gama variada de situações de ocupação de terras por grupos negros e ultrapassar o binômio fuga-resistência, instaurado no pensamento corrente quando se trata de caracterizar estas conformações sociais (SCHMITT; TURATTI; CARVALHO, 2002, p. 1-2).
\end{abstract}

Conforme apresentam Schmitt, Turatti e Carvalho (2002) para compreender a definição de identidade quilombola, há antes a necessidade de reconhecer que foram as relações com a terra e a necessidade de acesso e permanência à terra que gerou e ainda gera a construção de uma identidade quilombola entre alguns grupos no Brasil.

Entretanto, cada grupo dispõe de sistemas próprios de relação que os torna diferentes de outros grupos (dos não quilombolas) e, do mesmo modo, os torna iguais a grupos afins (quilombolas), igualmente assistidos por lei $^{2}$. Sendo assim, a "percepção da identidade social, da diferença que se constrói a partir da percepção do outro, é demonstrada a partir de categorias não tão emblemáticas em se tratando das relações raciais” (SOUZA, 2002, pp. 128129).

Além dos diversos fatores sociais e culturais que venham a definir os limites entre os

2 Artigo 68 do ADCT (Ato das Disposições Constitucionais Transitórias): Disponível em: $<<$ http://www.cpisp.org.br/htm/leis/fedl.htm $\gg>$ 
quilombolas e outros grupos, faz-se necessário dar atenção às diferenças que se mostram significativas para os próprios membros do grupo, como os parâmetros de auto-atribuição de uma identidade básica e identidade mais geral, que no caso das comunidades negras rurais costuma ser determinada pela origem comum do grupo e formação no sistema escravocrata (O'DWYER, 2002):

Essa referência a uma origem comum presumida parece recuperar, de certo modo, a própria noção de quilombo definida pela historiografia. Vale assinalar, contudo, que o passado a que se referem os membros desses grupos "não é o da ciência histórica, mas aquele em que se representa a memória coletiva" — portanto, uma história que pode ser igualmente lendária e mítica (O'DWYER, 2002, p. 17).

Com base no que afirma O’Dwyer (2002) entendemos que as versões sobre a origem das comunidades quilombolas não precisam, obrigatoriamente, estar conectadas a um passado histórico real, comprovado, mas aquele que tenha sido convencionado e assumido como verdadeiro pelos membros do grupo. Schmitt, Turatti e Carvalho (2002) também assinalam essas formações originadas de variados processos:

[...] os grupos que hoje são considerados remanescentes de comunidades de quilombos se constituíram a partir de uma grande diversidade de processos, que incluem as fugas com ocupação de terras livres e geralmente isoladas, mas também as heranças, doações, recebimento de terras como pagamento de serviços prestados ao Estado, a simples permanência nas terras que ocupavam e cultivavam no interior das grandes propriedades, bem como a compra de terras, tanto durante a vigência do sistema escravocrata quanto após a sua extinção (SCHMITT; TURATTI; CARVALHO, 2002, p. 3).

Reconhecer essa grande diversidade de processos apontada por Schmitt, Turatti e Carvalho (2002) permite compreender a construção das identidades quilombolas na/da comunidade de Jurussaca, tomando como referência seus próprios critérios e história. Assim, considerando a visão ampliada sobre as diversas origens e histórias desses grupos (remanescentes de quilombo) as identidades quilombolas na/da comunidade de Jurussaca se aproximam da "condição de coletividades camponesa, definida pelo compartilhamento de um território e de uma identidade" (SCHMITT; TURATTI; CARVALHO, 2002, p. 3):

[...] a condição de remanescente de quilombo é também definida de forma dilatada e enfatiza os elementos identidade e território. Com efeito, o termo em questão indica: a situação presente dos segmentos negros em diferentes regiões e contextos $e$ é utilizado para designar um legado, uma herança cultural e material que lhe confere uma referência presencial no sentimento de ser e pertencer a um lugar específico (SCHMITT; TURATTI; CARVALHO, 2002, p. 4, grifo do autor).

Conforme Schmitt, Turatti e Carvalho (2002) a compreensão do conceito de remanescente de quilombo está diretamente relacionada aos conceitos de identidade e território. Visto que o sentimento de pertença a um grupo ou a uma terra consiste em uma 
forma de expressão da identidade étnica e da territorialidade de um grupo. "Estes dois conceitos são fundamentais e estão sempre inter-relacionados no caso das comunidades negras rurais" (SCHMITT; TURATTI; CARVALHO, 2002, p. 4), uma vez que a presença, interesse, disputa e direitos entre brancos e negros sobre um mesmo espaço físico/social, deixa transparecer aspectos encobertos das relações raciais (GUSMÃO, p.14, apud SCHMITT; TURATTI; CARVALHO, 2002, p. 4).

Schmitt, Turatti e Carvalho (2002) acrescentam outra categoria relevante presente na relação entre identidades quilombolas e território: o parentesco. Segundo as autoras território e parentesco também formam identidades quilombolas, "na medida em que os indivíduos estão estruturalmente localizados a partir de sua pertença a grupos familiares que se relacionam a lugares dentro de um território maior" (SCHMITT; TURATTI; CARVALHO, 2002, p.4). Refletir sobre esses conceitos ajuda a compreender as identidades quilombolas que permeiam a comunidade de Jurussaca, atravessadas, por exemplo, por questões de parentesco, pertencimento (ao grupo e ao território), religiosidades, origem comum, dentre outras questões.

\section{IDENTIDADES NO JURUSSACA}

Reconhecer-se como quilombola e/ou pertencer a um território quilombola ou remanescente de quilombo não significa apenas fazer parte de uma comunidade reconhecida como quilombola, mas carregar identidades que vêm sendo construídas como fruto do processo histórico de formação da sociedade brasileira. Mas que não corresponde a verdade absoluta (generalizante) sobre esses grupos.

Olhar para uma comunidade quilombola de forma mais específica requer abrir mão da visão geral sobre quilombolas e comunidades quilombolas no Brasil, na busca de compreender a particularidade da comunidade estudada. As histórias de formação das comunidades quilombolas são diversas e provém de contextos sociais e históricos diferentes.

As comunidades quilombolas não são obrigatoriamente originárias de grupos de escravos fugidos, mas compõem grupos e/ou comunidades negras (urbanas ou rurais) que resistem (sobrevivem) socialmente a partir de seus modos de vida tradicionais. A comunidade de Jurussaca é uma comunidade afro-indígena, que muito se assemelha a outras comunidades rurais formadas nas fronteiras abertas entre o Pará e o Maranhão.

A seguir apresento algumas das identidades presentes na comunidade de Jurussaca, com base em observações, participações e entrevistas empreendidas na comunidade nos anos 
de 2015 e 2016. Optamos em utilizar algumas siglas para representar alguns dos moradores entrevistados.

\title{
2.1 SER PRETO, SER ARAÚJO
}

A comunidade quilombola de Jurussaca "aponta para forte influência afro-indígena, e o biótipo dos moradores de Jurussaca corrobora para essa miscigenação" (SILVA, 2014, p. 16). Na comunidade predomina entre os moradores os sobrenomes Silva e Araújo. Entretanto, para os moradores de Jurussaca é o sobrenome Araújo $^{3}$ que legitima a ancestralidade quilombola. Ter o sobrenome Araújo é, portanto, pertencer à "raça de quilombo" (dona F.) que deu origem a comunidade. Dona F. conta com orgulho que seu pai, Raimundo Eraldo de Araújo, era um quilombola porque era um Araújo:

\begin{abstract}
Não, eu sou Ramo. Como eu lhe disse ontem, o meu pai era Araújo nã? Minha mãe não, era Ramos e aí como eles não eram casados eu não puxei o Araújo. Minha mãe não, era Ramos e aí como eles não eram casados eu não puxei o Araújo. Só que a minha mãe era bem limpa e meu pai era moreno e eu saí assim morena. Ele era raça mesmo de quilombo ele. Ele era Araújo, Raimundo Eraldo de Araújo (dona F.).
\end{abstract}

Com base na fala de dona F., nota-se que o sobrenome Araújo legitima a identidade quilombola de alguns membros do grupo. Dona F. conta que não recebeu o sobrenome Araújo em virtude da união não oficializada entre seus pais: "Minha mãe não, era Ramos e aí como eles não eram casados eu não puxei o Araújo". Dona F. afirma que o pai dela "era raça mesmo de quilombo", que além de possuir o sobrenome Araújo tinha a cor morena. Assim, ter a pele preta também legitima a pertença à "raça de quilombo" de Jurussaca.

A cor da pele associada à identidade quilombola dos moradores da comunidade permite aproximar reflexões sobre os processos de construção dos limites étnicos ao longo da formação da comunidade, que se caracteriza por ser uma comunidade negra rural. Essa característica da comunidade "permite considerar que a afiliação étnica é tanto uma questão de origem comum quanto de orientação das ações coletivas no sentido de destinos compartilhados" (O'DWYER, 2002, p. 16).

A mãe de dona F., por sua vez, é denominada por ela como "pele limpa", a quem dona F. não categoriza como quilombola, em virtude do sobrenome Ramos e da pele branca. Desse

\footnotetext{
${ }^{3}$ O sobrenome Araújo, predominante na comunidade de Jurussaca é de origem galego-português. In: Almeida, 2010, s/p apud Silva, 2014. Ver em: SILVA, Jair Francisco Cecim. O Português Afro-Indigena de Jurussaca/PA: Revisitando a descrição do sistema pronominal pessoal da Comunidade a partir da textualidade. Tese (Doutorado em Filologia e Língua Portuguesa) - Faculdade de Filosofia, Letras e Ciências Humanas, Universidade de São Paulo. São Paulo: USP, 2014.
} 
modo, a cor da pele representa para dona F. o atributo de ser ou não quilombola na comunidade de Jurussaca, assim como o sobrenome Araújo.

Nota-se que a comunidade convencionou elementos que atribuem ou não a designação como quilombola aos membros do grupo. Essa construção sugere a existência de uma fronteira étnica, em que se encontram alguns membros do grupo (como os Araújo brancos, ou os Araújo sem sobrenome Araújo, ou os pretos que não são Araújo e ainda, as pessoas de fora do grupo). Essa fronteira étnica uma vez estabelecida no/pelo grupo serve como parâmetro para aqueles que estão fora desse grupo étnico.

Portanto, a comunidade se reconhece como quilombola pela cor da pele e pelo sobrenome comum. Esses elementos a identificam e a diferenciam de grupos que estão fora desse grupo étnico: sejam pessoas de outras comunidades, seja o pesquisador, ou mesmo representantes de órgãos governamentais (INCRA, INTERPA, Prefeitura etc.), dentre outros.

Dona F. também atribui a seu J. (seu esposo) como pertencente à "raça de quilombo" do Jurussaca. A referência utilizada para defini-lo é a mesma utilizada para fazer a definição de seu pai. Assim, ela afirma que seu J. é descendente direto dos antigos moradores da comunidade por ser um Araújo: "E o seu marido é daqui mesmo? É, ele é daqui mesmo. Ele é mesmo dos... dos... velhos mesmo daqui do Jurussaca. Dos Araújo mesmo, ele é Araújo, o pai dele. A mãe dele era de outra família, ela era branca que nem esta pequena aqui [...] (dona F.)".

Dona F. conta que seu J. é um Araújo e que descendente diretamente dos primeiros moradores da comunidade: "É, ele é daqui mesmo. Ele é mesmo dos velhos mesmo daqui do Jurussaca. Dos Araújo mesmo, ele é Araújo" (dona F.). Desse modo, ser um Araújo é ser um legítimo quilombola na comunidade. O sobrenome Araújo aproxima os moradores do Jurussaca de hoje do Jurussaca dos primeiros moradores.

Dona F. conta que a mãe de seu J. "era bem branca", de modo que a ela dona F. também não define como quilombola. Assim, a cor da pele (escura ou clara, preta ou limpa, morena ou branca) define quem é quilombola legítimo na comunidade.

Seu J.R. (outro senhor entrevistado) conta que os três primeiros moradores que chegaram à comunidade, uniram-se na formação de novas famílias e assim deram origem aos Araújo de Jurussaca: “... chegaram aqui, um morava ali, outro morava pra acolá, aí foram formando as famílias, já uma se entrosando com as outras. Aí já que ficou só uma família de Araújo aqui".

Seu J.R. não possui o sobrenome Araújo, mas diz que em sua família alguns já possuem o sobrenome: "Já tenho genro que é Araújo, já tenho dois, aí o negócio vai se 
misturando tudinho". Seu J.R. se refere às pessoas de sobrenome Araújo como uma grande família, proveniente da mistura (união) entre as primeiras famílias.

Assim como dona F, seu J.R. também define o grupo quilombola pela cor da pele: “Os quilombola vem da parte dos morenos, né? Daí da África”. Assim, nota-se que a cor da pele também é tomada por ele como elemento que marca as identidades da comunidade como quilombola. Além disso, ele estabelece a relação entre a cor da pele como uma herança histórica do processo de escravidão de africanos no Brasil ao fazer referência à África.

\title{
2.2 RELAÇÕES DE PARENTESCO
}

Um aspecto que marca a fronteira étnica na comunidade de Jurussaca é a manutenção da ideia de que a união marital deve ser preferencialmente estabelecida entre os membros da comunidade. Ainda que na concepção dos moradores o casamento entre parentes não seja correto há uma crença de que a união com as pessoas de outras comunidades não costuma ser promissora. Desse modo, a preferência pela união com pessoas da própria comunidade tende a manter a relação de parentesco entre os moradores.

\begin{abstract}
Eu pensava que eu não era primo da Lúcia, nós somos primos. Olha e eu tinha isso na minha cabeça. E eu dizia, não! Porque sempre diziam quando é parente da gente, a gente não namora, a gente não faz nada. Mas olha, pra tu ver que isso já vinha muito tempo na minha cabeça, porque era as três famílias e todas três era quase o mesmo sangue. Então não tem como a pessoa se livrar (seu V.).
\end{abstract}

Seu V. atribui essa condição (que predomina nas uniões maritais) à formação da comunidade, originária de três famílias. Percebida essa relação de parentesco que marca a formação da comunidade de Jurussaca, entendemos o parentesco como uma das características de organização social em uma mesma base étnica.

A marca de parentesco é característica comum no processo de formação de diversas comunidades quilombolas no Brasil ${ }^{4}$. Isso acontece porque a ocupação de terras para a produção familiar é assimilada como projeto camponês, cujo propósito (no Sul do Brasil) entre muitas comunidades quilombolas foi dispor de um pedaço de terra onde fosse possível trabalhar e promover o sustento familiar (SANTOS, 2010).

\footnotetext{
${ }^{4}$ Bastos (2007) desenvolveu seu estudo no quilombo de São José da Serra, no Rio de Janeiro a partir de sua organização territorial e destaca a relação de parentesco estabelecida entre os moradores de Valença. Santos (2007) também procura explorar alguns aspectos de sua organização social da comunidade quilombola Tapuio, no Piauí, a partir da relação de parentesco, assim como de pertencimento. Scoles (2007) faz um estudo sobre território, biodiversidade e organização social na de Itacoã, nessa abordagem também discute às questões de parentesco.
} 
Santos (2010) afirma que a partir da transição do trabalho escravo para o trabalho livre, as terras devolutas do Mato Grosso estavam à espera de compra, com um número elevado de posseiros, a maioria sem condições de regularizar suas posses. Essas terras ficaram sobre as posses de grupos familiares, que as utilizavam em pequenas escalas produtivas, com fins de sobrevivência. Essa situação se estendeu a diversas regiões do Brasil e pode ser observada na comunidade de Jurussaca, segundo é possível observar pelo processo de formação da comunidade, conforme contam os seus moradores.

Para compreender a relação de parentesco predominante na comunidade nas uniões maritais, tomam-se como base as definições feitas por Dumont (1971) em um nível local e parental, em que a afinidade está englobada na consanguinidade:

[...] afastamos um pouco da letra d'As Estruturas... dizendo que a proibição do incesto testemunha uma incompatibilidade, logo uma complementaridade entre consangüinidade e afinidade, sempre presente em algum grau, e que as sociedades que praticam o casamento entre primos cruzados apresentam esta oposição em sua forma mais lógica e completa (DUMONT, 1971, p. 93).

De acordo com Dumont (1971) as sociedades ou grupos que praticam casamentos maritais entre parentes (casamento consanguíneos), reconhecendo as uniões como legítimas e/ou necessárias para o grupo, colocam-se em oposição a uma lógica (regra-geral) da sociedade, assumindo assim um nexo comum de parentesco/sangue. Para Dumont (1971) enquanto os indianos reconheciam as exigências da casta, adotavam algo a mais que a noção de um nexo.

Toda sociedade apresenta regras de casamento que, por sua vez, oferecem implicações estruturais maiores que as do arranjo dos grupos. Na comunidade de Jurussaca o casamento consanguíneo entre os membros do grupo não funciona como regra previamente estabelecida como as castas indianas estudadas e exemplificadas por Dumont (1971), mas sua aceitação coletiva pode ser compreendida como um nexo comum adotado pelo grupo.

Mesmo que a comunidade reconheça as relações consanguíneas e de parentesco nas uniões maritais, essas uniões são justificadas pelos membros do grupo não pela consanguinidade ou parentesco, mas pela afinidade existente entre os membros do grupo, sendo assim, a afinidade "é exterior ao parentesco propriamente dito" (DUMONT, 1971, p. 93). 


\title{
2.3 REDES DE PARENTESCO E PERTENCIMENTO
}

$\mathrm{Na}$ comunidade de Jurussaca a relação estabelecida entre os moradores e as terras da comunidade se assemelhou por muito tempo às realidades de outras regiões do Brasil (manutenção do sustento familiar). Porém, a partir dos processos de luta pelo território e do reconhecimento como quilombola, surgiu na comunidade um novo projeto social: agora não apenas para manutenção e sustento familiar, mas para a preservação das terras sobre as posses da comunidade (por meio da luta).

Em função desse contexto uma força comunitária, que antes se organizava apenas para o trabalho coletivo, passou a assumir um novo papel: a luta pela posse da terra. Essa força comunitária pode ser compreendida pela formação da rede de parentesco ${ }^{5}$, que se estabelece para além das relações consanguíneas.

Os moradores da comunidade de Jurussaca costumam exercer as atividades produtivas na terra de forma coletiva, construindo as redes de solidariedade (redes de parentesco), assim como na formação de irmandades para organização das festividades religiosas (também entendidas como redes de parentesco).

Sobre as redes de solidariedades Almeida (2008) afirma que:

\begin{abstract}
Por seus desígnios peculiares, o acesso aos recursos naturais para o exercício de atividades produtivas, se dá não apenas através das tradicionais estruturas intermediárias do grupo étnico, dos grupos de parentes, da familia, do povoado ou da aldeia, mas também por um certo grau de coesão e solidariedade obtido face a antagonistas e em situações de extrema adversidade e de conflito, que reforçam politicamente as redes de solidariedade (ALMEIDA, 2008, p. 29).
\end{abstract}

As redes de parentesco em comunidades quilombolas se fundamentam com base na família comunitária. A princípio os núcleos familiares da comunidade de Jurussaca se organizavam para o trabalho coletivo na terra, mas nesse contexto específico assumiu uma organização de luta e reivindicação pela terra, que mais tarde se articulou para a criação da associação de moradores.

Outro elemento presente nas identidades da comunidade de Jurussaca é o sentimento pertencimento ao grupo social e ao território. O pertencimento também se baseia no

\footnotetext{
${ }^{5}$ Tais redes de parentesco, redes sociais ou redes (como são conhecidas) comumente marcam a vida social de comunidades quilombolas, "embora não estritamente econômicas, dependendo de relações de parentesco, que definem direitos diferenciados ao patrimônio territorial compartilhado, do mercado e das relações de aliança e oposição com outros agentes presentes no espaço rural, inclusive no plano da política municipal, e mesmo que perpassadas pelas adesões ao movimento social e pelas relações com as agências estatais, têm como mote primeiro buscar alternativas às condições de vida tornadas crescentemente precárias, desde o cotidiano imediato, até os projetos e expectativas avaliados como possíveis de serem realizados" (PAOLIELLO, 2007, p.141) In: PAOLIELLO, Renata Medeiros: Remanescentes de Quilombos: Redes sociais e processos políticos. São Paulo: Perspectivas, v. 32, jul. - dez., p. 127-159, 2007.
} 
compartilhamento de valores comuns de um mesmo grupo, que se organiza a fim de se preservar unido por um sentimento comum ou, ainda, o sentimento pessoal de pertencer ao grupo.

O pertencimento é a construção de laços pessoais entre os membros de um grupo, com base no reconhecimento mútuo e no sentimento de adesão aos princípios definidos pelo grupo (WEBER, 2008). É, ainda, a partilha de memórias comuns desse grupo.

O cotidiano dos moradores da comunidade de Jurussaca é tomado por diversos aspectos que marcam o sentimento de pertencimento, que são comuns ao grupo, seja na relação com a natureza, nos sistemas de crenças dos moradores, ou mesmo nas memórias comuns partilhadas pelos membros do grupo.

A relação de pertencimento entre os moradores da comunidade está nas crenças subjetivas que são acatadas pelo grupo a partir de sua origem comum. A origem comum da comunidade e a crença nessa origem fortaleceu a luta da comunidade pela terra e por seu reconhecimento.

A comunidade se forma na coletividade, compartilhando um sistema cultural, valores, aspirações e medos. Esses compartilhamentos acontecem de forma espontânea nas vivências cotidianas dos moradores e se intensificaram diante da necessidade dos moradores permanecerem em suas terras, de tê-las sobre sua posse.

O pertencimento por muitas vezes destaca em um grupo social suas características culturais. Os sistemas de crença dos moradores são entendidos aqui como as diversas simbologias adotadas pela comunidade para organizar e interpretar o próprio cotidiano, através de contatos variados, nas relações entre as pessoas, na relação com a natureza e na forma de interpretá-la e em suas religiosidades. Porém, não há intenção de fazer aprofundamentos neste momento sobre os sistemas de crenças da comunidade, mas entender o pertencimento como resultado de um processo de integração entre seus membros (WEBER, 2008).

Essa integração é percebida tanto pelo sentimento de adesão ao grupo, quanto pelos valores comuns que circulam na comunidade, assim como por seus sistemas de crença. Nesse sentido, a comunidade de Jurussaca é um grupo aberto, dado seu processo de formação com inserção de pessoas de outras comunidades, mas relativamente fechado (seja pela união marital predominante entre seus membros, seja pelas relações com os visitantes).

Do mesmo modo que acontecem adesões, acontecem exclusões de indivíduos de um grupo (WEBER, 2008), que atende aos seus próprios critérios. O sentimento de pertencimento à comunidade quilombola de Jurussaca está muitas vezes nas relações dos moradores com seu 
território étnico e não necessariamente nas relações interpessoais entre seus membros. Os territórios étnicos são configurações do que a comunidade construiu coletivamente, mas também do que o território representa para cada um de seus membros.

Seu J.R. diz se sentir um quilombola, por estar na comunidade e fazer parte dela, ainda que seu convívio com alguns moradores não seja tão amistoso. Apesar da relação estremecida entre seu J.R. e outros moradores e o fato de ele não ter nascido na comunidade, seu Joãozinho assume a identidade quilombola: "Eu sou quilombola, eu tô aqui, eles não me aceitam, mas em tudo eu tô no meio" (seu J.R.).

A identificação de seu J.R. como quilombola se conforma no sentimento de pertencimento à comunidade. Quando seu Joãozinho diz "eles não me aceitam" se refere às pessoas da comunidade. A sua não aceitação por parte do grupo não o retira do grupo, mas deixa escapar as relações que se estabelecem entre eles, que se constroem a partir dos valores e das vivências partilhadas internas ao grupo.

Assim, as vivências entre seu J.R. e a comunidade não interferem na consciência de identidades quilombola de nenhuma das partes, uma vez que o território étnico lhes é comum (compartilhado). Sendo assim, os "princípios classificatório que fundamenta a existência do grupo emana da construção de um repertório de ações coletivas e de representações face a outros grupos" (ALMEIDA, 2011, p. 84).

Almeida (2011) explicita que é nas ações coletivas e de representações de um grupo em relação a outro que se estabelecem os princípios classificatórios de existência do grupo. A luta pela posse da terra e titulação das terras da comunidade representa uma ação coletiva da comunidade em prol do interesse comum.

Em todo o caso, "não se está diante de um a priori histórico, jurídico, arqueológico ou sociológico, e sim de uma afirmação identitária pela contraposição, através da auto atribuição" (MARQUES, 2008, p. 16), a luta da comunidade representou sua auto atribuição como quilombola (como os donos da terra) em contraposição ao grupo de fazendeiros (externo à comunidade) que possuía interesses alheios aos da comunidade.

O engajamento de seu J.R. revela que apesar dos conflitos internos entre os moradores da comunidade, a união da comunidade por meio de sua condição étnica para um bem comum revela a etnicidade como um instrumento político (WEBER, 2008). Entende-se dessa maneira que "as distinções étnicas não dependem de uma ausência de interação social e aceitação, mas são, muito ao contrário, frequentemente as próprias fundações sobre as quais são levantados os sistemas sociais englobantes" (BARTH, 2011, p. 186). 
O pertencimento ou o não pertencimento à comunidade de Jurussaca coloca em discussão não apenas a ideia de pertencimento ao território comunitário, mas, sobretudo, o pertencimento étnico. Assim, a relação de pertencimento dos membros do grupo sinaliza o quanto as identidades "são imbricadas na semelhança a si próprio, e na identifícação e diferenciação com o outro e se constituem em foco central nas relações sociais” (LIMA, 2008, p. 39), sendo que essas relações são construídas continuamente a partir de repertórios culturais e históricos de matrizes africanas (LIMA, 2008).

Tratar a questão da etnia neste trabalho é considerar as identidades e territórios étnicos do ponto de vista da própria comunidade. Há nessa situação o vínculo solidário entre seus moradores (redes de parentesco). Identidades étnicas e territórios étnicos se configuram a partir da formação de grupos étnicos.

A Constituição Federal de 1988 passou a validar em seu texto de lei que a união de grupos tradicionalmente organizados seja reconhecida como quilombola. A organização coletiva das comunidades remanescentes quilombolas e/ou quilombolas se configuram como grupos étnicos formados.

As comunidades quilombolas e/ou remanescentes quilombolas têm resistido socialmente a partir de suas próprias organizações, marcadas por processos de exclusão e inclusão, permitindo assim delimitar suas fronteiras étnicas (BARTH, 2011). Nesse sentido:

\footnotetext{
Na medida em que os atores usam identidades étnicas para categorizar a si mesmos e outros, com objetivos de interação, eles formam grupos étnicos neste sentido organizacional. (Ou então) o ponto central da pesquisa torna-se a fronteira étnica que define o grupo e não a matéria cultural que ela abrange. As fronteiras às quais devemos consagrar nossa atenção são, é claro, as fronteiras sociais, se bem que elas possam ter contrapartidas territoriais (BARTH, 2011, p. 195).
}

A organização da comunidade quilombola de Jurussaca, no trabalho coletivo, organização e divisão de seus espaços, reivindicações de seus direitos etc., está diretamente relacionado ao território. O território é a base das identidades da comunidade de Jurussaca, em função de sua territorialização, reterritorialização, luta pela posse da terra e titulação coletiva das terras.

\section{CONSIDERAÇÕES FINAIS}

A partir das interpretações e reflexões feitas sobre a construção da identidade social dos moradores da comunidade de Jurussaca como quilombolas, identificamos que a comunidade elaborou uma identidade quilombola com base na origem comum, na luta pela 
posse da terra e na titulação coletiva das terras. Mas entre os moradores sua legitimidade encontra-se, sobretudo, na cor da pele (ser preto) e no sobrenome comum (Araújo).

Esses quatro elementos estão, portanto, em plano principal de suas identidades. Os dois primeiros são reafirmados constantemente em suas falas. Os dois últimos, porém, apesar de serem reincidentes nas falas dos moradores, são apresentados de forma indireta, quando os moradores associam ao sobrenome Araújo e a cor preta à "raça de quilombos" que deu origem à comunidade. A partir desses dois elementos se estabelecem as fronteiras étnicas entre os membros do grupo e os outros. Em um segundo plano se encontram outros elementos, como as relações de parentesco, o pertencimento e as redes de parentesco.

Os elementos dos dois planos representam as identidades quilombolas circulantes na comunidade de Jurussaca. Mas representam, além disso, um grupo cuja formação recebeu forte influência afro-indígena, que representa a população amazônica, em especial as comunidades da Região do Salgado Paraense.

Compreendemos assim, que as identidades quilombolas da comunidade se construíram em seus próprios sistemas sociais, desde sua origem, passando pelo apossamento e uso comum da terra (comum na estrutura agrária brasileira) até chegar aos fatores étnicos que contribuíram para o reconhecimento da comunidade como quilombola. Assim, os moradores da comunidade de Jurussaca, apresentam na base de suas identidades o processo de ocupação territorial, assinalada por Silva (2014) como afro-indígena, cujos indícios dessa formação são percebidos no cotidiano da comunidade.

Desse modo, encerramos neste artigo um pequeno olhar lançado às identidades quilombolas na/da comunidade de Jurussaca, mas deixamos o caminho aberto para outras possibilidades de leitura sobre a comunidade, seus moradores, suas identidades, territorialidades e religiosidades.

\section{REFERÊNCIAS}

ALMEIDA, Alfredo Wagner B. Quilombolas e novas etnias. Org. ALMEIDA, Alfredo Wagner B. Manaus: UEA Edições, 2011.

Terras de Quilombos, Terras Indígenas, "Babaçuais Livres", "Castanhais do Povo", Faxinais e Fundos de Pastos: Terras tradicionalmente ocupadas. 2 ed. Manaus: PGSCA-UFAM, 2008.

BARTH, Fredrik. Grupos Étnicos e Suas Fronteiras. In: POUTIGNAT, Philippe; STREIFF_FERNART, Jocelyne. Teorias da Etnicidade: Seguido de grupos étnicos e suas fronteiras de Fredrik Barth. Tradução de Elcio Fernandes. São Paulo: UNESP, 2011. 
HALL, Stuart. Da Diáspora: Identidades e mediações culturais. Belo Horizonte: UFMG, 2003.

LIMA, Maria Batista. Identidade Étnico/Racial no Brasil: Uma reflexão teóricometodológica. S/l: Revista Fórum de Identidades. Ano 2, v. 3, jan-jun, pp. 33-46, 2008. 136

LitTle, PAUl E. Territórios Sociais e Povos Tradicionais no Brasil: Por uma Antropologia da territorialidade. Rio de Janeiro: Tempo Brasileiro. Anuário Antropológico 2002-2003, pp 251-290, 2004.

MARQUES, Carlos Eduardo. Remanescentes das Comunidades de Quilombos, da Ressignificação ao Imperativo Legal. Dissertação (Mestrado em Antropologia) Departamento de Antropologia e Sociologia de Minas Gerais. Belo Horizonte: UFMG, 2008.

O‘DWYER, Eliane Cantarino. Os Quilombos e a Prática Profissional dos Antropólogos. In: Quilombos: Identidade étnica e territorialidade. O`DWYER, Eliane Cantarino (Orga.). Rio de Janeiro: Fundação Getúlio Vargas, pp. 13-42, 2002.

PAOLIELLO, Renata Medeiros: Remanescentes de Quilombos: Redes sociais e processos políticos. São Paulo: Perspectivas, v. 32, jul. - dez., p. 127-159, 2007.

SANTOS, Carlos Alexandre B. P. Negros do Tapuio: Estudo etnográfico de uma comunidade quilombola do semi-árido piauiense. 2 ed. In: BRASIL. Prêmio Territórios Quilombolas.. Brasília: Ministério do Desenvolvimento Agrário - MDA, 2007.

Fiéis Descendentes: Redes-irmandades na pós-abolição entre as comunidades negras rurais Sul-Mato-Grossenses Tese (Doutorado em Antropologia Social) - Programa de Pós Graduação em Antropologia Social da Universidade de Brasília, Brasília: UnB, 2010.

SCOLES, Ricardo. Comunidade Negra de Itacoã: Território, biodiversidade e organização social, pilares para o etnodesenvolvimento? 2 ed. In: BRASIL. Prêmio Territórios Quilombolas. Brasília: Ministério do Desenvolvimento Agrário - MDA, 2007.

SCHMITT, Alessandra; TURATTI, Maria Cecília Manzoli; CARVALHO, Maria Celina Pereira. A Atualização do Conceito de Quilombo: Identidade e território nas definições teóricas. In: Comunicação de Resultados de Pesquisa/Research Results. S/l: Ambiente \& Sociedade, n. 10, 2002.

SILVA, Jair Francisco Cecim. O Português Afro-Indígena de Jurussaca/PA: Revisitando a descrição do sistema pronominal pessoal da Comunidade a partir da textualidade. Tese (Doutorado em Filologia e Língua Portuguesa) - Faculdade de Filosofia, Letras e Ciências Humanas, Universidade de São Paulo. São Paulo: USP, 2014.

SOUZA, Vânia Rocha Fialho de Paiva. Conceição das Crioulas, Salgueiro (PE). In: Quilombos: Identidade étnica e territorialidade. O'DWYER, Eliane Cantarino (Orga.). Rio de Janeiro: Fundação Getúlio Vargas, pp. 109-140, 2002.

WEBER, Max. Conceitos Básicos de Sociologia. São Paulo: Editora Moraes, 1987. WEBER, Max. Economia e Sociedade. 3 ed. Brasília: Editora UNB, 2008. 